\title{
Foodborne Pathogen Assessment in Raw Milk Cheeses
}

\author{
Nicola Costanzo $\mathbb{D}^{1}{ }^{1}$ Carlotta Ceniti, ${ }^{1}$ Adriano Santoro, ${ }^{2}$ Maria Teresa Clausi, ${ }^{3}$ \\ and Francesco Casalinuovo ${ }^{3}$ \\ ${ }^{1}$ Department of Health Sciences, University "Magna Groecia” of Catanzaro, Campus Universitario "S. Venuta”, Viale "S. Venuta", \\ I-88100 Catanzaro, Italy \\ ${ }^{2}$ Department of Veterinary Medicine and Animal Production, University "Federico II" of Naples, Via Delpino 1, 80100 Napoli, Italy \\ ${ }^{3}$ Istituto Zooprofilattico Sperimentale del Mezzogiorno, Viale Crotone, Catanzaro 88100, Italy
}

Correspondence should be addressed to Nicola Costanzo; costanzo.nic@unicz.it

Received 20 September 2019; Accepted 11 December 2019; Published 22 January 2020

Academic Editor: Alessandro Di Cerbo

Copyright (c) 2020 Nicola Costanzo et al. This is an open access article distributed under the Creative Commons Attribution License, which permits unrestricted use, distribution, and reproduction in any medium, provided the original work is properly cited.

\begin{abstract}
General hygienic parameters and selected foodborne pathogens in raw milk cheeses at the retail level were evaluated. A total of 245 raw milk cheese samples were analysed for total bacterial count, Enterobacteriaceae, E. coli, Salmonella spp., Listeria monocytogenes, coagulase-positive Staphylococci, and staphylococcal enterotoxin. Results showed only 3 samples that were not compliant with European rules on staphylococcal enterotoxin, but coagulase-positive Staphylococci were evidenced in all samples tested. Salmonella spp. and Listeria monocytogenes were never detected whereas E. coli was evidenced in 20 samples. Results suggest a need for improvement of good manufacturing practice and milking operation.
\end{abstract}

\section{Introduction}

In recent years, small-scale artisanal cheese production has increased worldwide and in Italy too. Raw milk is becoming frequently used in cheese production and gaining popularity among consumers who recognize raw milk cheese as healthier and as a better representative of the local food tradition. Unpasteurized milk allows the natural enzymes and microflora proteolysis and lipolysis activity to enhance desirable flavour characteristics [1]. Growth of pathogens is hindered by several factors such as speed of curd acidification and final product $\mathrm{pH}$; time and temperature used to rinse the curd; the presence in milk of natural protection systems such as lactoperoxidase, lysozyme, and lactoferrin, well known for their antibacterial activity [2]; and production of bacteriocins or a bacteriocin-like compound by lactic acid bacteria [3]. Additionally, the cheese made from milk that has not undergone heat treatment may represent a food safety concern especially for consumers under special medical and physiologicalmodified conditions. Although pathogens like Salmonella, Listeria monocytogenes, verotoxigenic Escherichia O157, and Staphylococcus aureus are often part of the animal intestinal microbiota, they can be isolated from the udder of healthy dairy animals or from operators' hands, and thus, they can easily contaminate the milk during the milking process [4].

Listeria monocytogenes represents one of the main concerns for ready-to-eat (RTE) food including raw milk cheeses, due its high mortality rate [5] especially for individuals at higher risk, e.g., pregnant women and immunocompromised people. In 2017, EFSA reported 2480 [6] confirmed invasive human cases of listeriosis and a prevalence rate of $0.9 \%$ in soft and semisoft cheeses made from raw or low-heattreated milk. Listeria monocytogenes presence in raw milk and cheese has been widely reported [7], and its ubiquitous nature and distribution contamination may occur at any stage of the production chain.

Salmonella spp. still represents the first causative agent of foodborne outbreak in EU: 9600 human cases, 2227 hospitalisations. Salmonella, the causative agent of foodborne outbreaks associated with the consumption of various types of cheese [8], can be detected in the intestinal tract of healthy animals, and contamination of milk mainly occurs during milking operations [9]. 
Staphylococcus aureus, cause a typical food poisoning which is characterized by nausea, vomiting, and diarrhoea $[10,11]$, and it is linked to consumption of food contaminated by one or more preformed enterotoxins [11] that are produced when the bacterial load exceeds $10^{5} \mathrm{CFU} / \mathrm{g}$ [12]. Staphylococcal food poisoning due to soft cheese made from raw milk has been recently reported [13].

E. coli occurrence in raw milk, in particular serotype 0157-H7, is well documented and represents a concern since up to $10 \%$ of people infected with these bacteria develop haemolytic uremic syndrome (HUS), which is potentially a lethal condition, especially in children [14]. In 2018, EFSA reported a total of 5079 foodborne outbreaks of which 14, involving 775 people, were linked to cheese consumption, and the most common causative agents were Shiga toxin-producing E. coli (STEC) and bacterial toxin [6].

Food safety criteria for staphylococcal enterotoxins, Salmonella, and Listeria monocytogenes in cheeses made from raw milk or milk that has undergone a lower heat treatment than pasteurization are laid down in Regulation 1441/2007 [15].

The present study was aimed at assessing the prevalence of target pathogens and enterotoxins in raw milk cheese samples collected at the retail level in Italy.

\section{Materials and Methods}

2.1. Sample Collection. From January to December 2018, a total of 245 raw milk cheese samples, singularly packaged from the manufacturer, were collected from local markets located in Italy (Calabria region). Among those, 182 originated from ovine, 27 from bovine, and 36 were produced using a mixture of bovine and ovine milk. Ovine cheese samples were categorized into the two following groups: the hard cheese category (80 samples) with a ripening period $\geq 60$ days and the soft cheese category (102 samples) with a ripening period of $\leq 60$ days. Bovine cheese samples consisted in two different categories: the soft cheese category (18 samples) and the pasta filata cheese category (9 samples). All mixed milk cheese samples (36 samples) belonged to the soft cheese category. Following collection, cheese samples were kept at $4^{\circ} \mathrm{C}$ and they were transported to the laboratory where analysis was carried out within 4 hours.

2.2. Sample Preparation. For each sample, an amount of $25 \mathrm{~g}$ of cheese was removed with a sterile blade, placed into a sterile stomacher bag, and subsequently homogenized in $225 \mathrm{~mL}$ of a quarter-strength Ringer solution (BR0052, Oxoid Ltd., Hampshire, UK) for 2 minutes using a Stomacher (Seward Laboratory Stomacher 400 Lab Blender, UK). Tenfold dilutions per homogenate sample were performed.

2.3. Total Viable Counts and Enterobacteriaceae and Escherichia coli Enumeration. Total bacterial count (TBC) and Enterobacteriaceae and E. coli enumeration were performed by the culture method. Thus, one $\mathrm{mL}$ from dilution was inoculated onto Plate Count Agar (PCA, CM0325, Oxoid Ltd.) and incubated for five days at $32^{\circ} \mathrm{C}$, onto Violet
Red Bile Glucose Agar (VRBGA, CM1082, Oxoid Ltd.) and incubated for $24 \mathrm{~h}$ at $37^{\circ} \mathrm{C}$, and onto RAPID Escherichia agar (Bio-Rad, Reinach, Switzerland) for $24 \mathrm{~h}$ at $37^{\circ} \mathrm{C}$ for $\mathrm{TBC}$, Enterobacteriaceae enumeration, and E. coli enumeration, respectively.

2.4. Staphylococcus Coagulase-Positive Enumeration and Enterotoxin Detection. For Staphylococcus coagulase-positive (SCP) enumeration, $0.1 \mathrm{~mL}$ from each dilution was spread onto Baird-Parker+Rabbit Plasma Fibrinogen according to ISO $6888-1 / 2(2004)$ and incubated at $37^{\circ} \mathrm{C}$ for $48 \mathrm{~h}$. Following the incubation period, five colonies per plate were tested for Gram coloration, catalase (Sigma-Aldrich, St. Louis, USA), coagulase (Thermo Fisher, Waltham, USA), and thermonuclease (Sigma-Aldrich, St. Louis, USA) and then phenotypically identified by the API Staph system (bioMérieux, Marcy-l'Étoile, France).

The presence of enterotoxin was assessed using the automated VIDAS Staph enterotoxin II, SET 2 (bioMérieux, Marcy-l'Étoile, France) based on an enzyme-linked fluorescent assay according to the instructions of the manufacturer.

2.5. Salmonella Detection. Salmonella analyses were done in accordance with ISO 6579:09 using a two-step enrichment procedure. Briefly, $10 \mathrm{~mL}$ of cheese from each sample was preenriched in $90 \mathrm{~mL}$ of Buffered Peptone Water (BPW, CM1049, Oxoid Ltd.) for $24 \mathrm{~h}$ at $37^{\circ} \mathrm{C}$. Then, $1 \mathrm{~mL}$ of the preenriched broth was transferred into $10 \mathrm{~mL}$ of MullerKauffmann Tetrathionate-Novobiocin Broth (CM1048, Oxoid Ltd.) supplemented with Novobiocin Selective Supplement (SR0181, Oxoid Ltd.) according to the manufacturer's instructions and incubated for $24 \mathrm{~h}$ at $37^{\circ} \mathrm{C}$; moreover, $0.1 \mathrm{~mL}$ of the preenriched broth was also inoculated onto $10 \mathrm{~mL}$ of Rappaport-Vassiliadis Soya Peptone Broth (CM0866, Oxoid Ltd.) and incubated for $24 \mathrm{~h}$ at $41.5^{\circ} \mathrm{C}$. Subsequently, each enriched broth was spread onto different selective media of Mannitol Lysine Crystal Violet Brilliant Green Agar (MLCB Agar, CM0783, Oxoid Ltd.) and onto Xylose-Lysine-Desoxycholate Agar (XLD Agar, CM0469, Oxoid Ltd.) using a sterile loop and incubated for $24 \mathrm{~h}$ at $37^{\circ} \mathrm{C}$. Colonies were identified using the API $20 \mathrm{E}$ system (bioMérieux, Marcy-l'Étoile, France) according to the manufacturer's indications.

2.6. Listeria monocytogenes Detection. In accordance with ISO 11290-1:2004, detection of L. monocytogenes was carried out by suspending $10 \mathrm{~g}$ of cheese in $90 \mathrm{~mL}$ of Fraser Broth (CM0895, Oxoid Ltd.) with Half Fraser Supplement (SR0166, Oxoid Ltd.) and incubating for $24 \mathrm{~h}$ at $30^{\circ} \mathrm{C}$. Subsequently, $0.1 \mathrm{~mL}$ of the first enrichment broth was suspended in $10 \mathrm{~mL}$ of Fraser Broth (CM0895, Oxoid Ltd.) with Fraser Supplement (SR0156, Oxoid Ltd.) and then incubated for $24 \mathrm{~h}$ at $37^{\circ} \mathrm{C}$. One loopfull of the enrichment broth was then streaked onto PALCAM Agar (CM0877, Oxoid Ltd.) added with PALCAM Selective Supplement (SR0150, Oxoid Ltd.) and onto Chromogenic Listeria Agar (CM1084, Oxoid Ltd.) supplemented with Listeria Selective Supplement (SR0226, Oxoid Ltd.) and Listeria Differential Supplement (SR0244, Oxoid Ltd.). Both plates were incubated for $48 \mathrm{~h}$ at $37^{\circ} \mathrm{C}$, then 
TABLE 1: Total bacterial count of cheese samples according to cheese categories.

\begin{tabular}{|c|c|c|c|c|c|c|}
\hline \multirow[b]{2}{*}{ Cheese made from ovine milk } & \multirow[t]{2}{*}{ Number of samples } & \multicolumn{4}{|c|}{$\begin{array}{c}\text { Number and (\%) of samples at different levels of TBC } \\
(\log \text { CFU/g) }\end{array}$} & \multirow[b]{2}{*}{$>8<9$} \\
\hline & & $<5$ & $>5<6$ & $>6<7$ & $>7<8$ & \\
\hline Soft cheese & 102 & $20(19.6)$ & $22(21.6)$ & $33(32.4)$ & $15(14.7)$ & $12(11.7)$ \\
\hline Hard cheese & 80 & $11(13.8)$ & $32(40)$ & $12(15)$ & $18(22.5)$ & $7(8.7)$ \\
\hline \multicolumn{7}{|l|}{ Cheese made from bovine milk } \\
\hline Hard cheese & 18 & $1(5.6)$ & $6(33.3)$ & $8(44.4)$ & $2(11.1)$ & $1(5.6)$ \\
\hline Pasta filata & 9 & $5(55.6)$ & $4(44.4)$ & $0(0.0)$ & $0(0.0)$ & $0(0.0)$ \\
\hline \multicolumn{7}{|l|}{ Cheese made from mixed milk } \\
\hline Hard cheese & 36 & $3(8.2)$ & $11(30.6)$ & $11(30.6)$ & $6(16.7)$ & $5(13.9)$ \\
\hline
\end{tabular}

TABLE 2: Enterobacteriaceae and E. coli counts of cheese samples according to cheese categories.

\begin{tabular}{|c|c|c|c|c|c|c|}
\hline \multirow[b]{2}{*}{ Cheese made from ovine milk } & \multirow[t]{2}{*}{$\begin{array}{c}\text { Number of } \\
\text { samples }\end{array}$} & \multicolumn{3}{|c|}{$\begin{array}{c}\text { Number and (\%) of samples at different } \\
\text { levels of Enterobacteriaceae }\end{array}$} & \multicolumn{2}{|c|}{$\begin{array}{c}\text { Number and (\%) of samples at } \\
\text { different levels of E.coli (log CFU/g }\end{array}$} \\
\hline & & $<2$ & $>2<3$ & $>3<4$ & $<2$ & $>2<3$ \\
\hline Soft cheese & 102 & $8(7.8)$ & $3(2.9)$ & $2(1.9)$ & $6(5.8)$ & $4(3.9)$ \\
\hline Hard cheese & 80 & $1(1.3)$ & $1(1.3)$ & $1(1.3)$ & $2(2.5)$ & $2(2.5)$ \\
\hline \multicolumn{7}{|l|}{ Cheese made from bovine milk } \\
\hline Hard cheese & 18 & $2(11.1)$ & $2(11.1)$ & $0(0.0)$ & $1(5.5)$ & $0(0.0)$ \\
\hline Pasta filata & 9 & $0(0.0)$ & $0(0.0)$ & $0(0.0)$ & $0(0.0)$ & $0(0.0)$ \\
\hline \multicolumn{7}{|l|}{ Cheese made from mixed milk } \\
\hline Hard cheese & 36 & $2(5.6)$ & $3(8.3)$ & $0(0.0)$ & $2(5.6)$ & $3(8.3)$ \\
\hline
\end{tabular}

Listeria monocytogenes presumptive colonies were biochemically identified by using the API Listeria System according to manufacturer's instructions (bioMérieux).

\section{Results}

The results of TBC, reported in Table 1, showed a high bacterial load in all samples tested. Soft cheese samples made from ovine milk evidenced the highest TBC level since more than $50 \%(n=60)$ of the samples analysed showed a TBC greater than $6 \log \mathrm{CFU} / g$; in the same category, hard cheese showed a lower contamination rate since more than $50 \%$ of the samples analysed $(n=43)$ showed a TBC count below 6 $\log$ CFU/g. In cheese made from bovine milk, pasta filata cheeses samples showed the lowest TBC range: enumeration in all samples ranged between 5 and $6 \log$ CFU/g differently from hard cheese samples where a TBC level above 6 log $\mathrm{CFU} / \mathrm{g}$ was evidenced in all samples tested. Overall, cheese from bovine milk showed lower TBC enumeration compared to ovine and mixed milk cheeses.

The results of Enterobacteriaceae enumeration are reported in Table 2. Out of 245 cheese samples, 25 resulted positive for Enterobacteriaceae, and among these, E. coli was evidenced in 20 samples.

With regard to cheese category and milk origin, ovine milk soft cheeses resulted in the highest number of $E$. colipositive samples. Out of the $20 \mathrm{E}$. coli-positive samples, 10 belonged to the soft cheese category, all made from ovine milk, and 10 to hard cheese: 4 were produced from ovine milk, 1 was produced from bovine milk, 3 were produced from a mix of ovine and bovine milk cheese, and 2 were from a mix of goat and ovine cheese. Additionally, in all samples positive for Enterobacteriaceae and E. coli, the contamination rate was very similar suggesting that most of the Enterobacteriaceae were $E$. coli.

SCP were isolated in all samples analysed: the average count was $2.52 \log \mathrm{UFC/g}$. Out of 245 samples analysed, 55 showed a SCP contamination level of $5 * 10^{5}: 37$ were cheese made from ovine milk ( 25 soft cheese and 12 hard cheese), 13 were cheese made from bovine milk (pasta filata), and 5 were from mixed milk cheese. All samples exceeding the $5 \mathrm{log}$ threshold level, specified in Regulation (EC) 1441/2007, were tested for enterotoxin: 3 samples, all cheeses made from ovine milk, were positive for enterotoxin and the isolates were identified as S. aureus, S. epidermidis, and S. warneri.

Listeria monocytogenes and Salmonella were never detected in all samples tested.

\section{Discussion}

Raw milk cheeses are an important part of the Italian cheese making tradition since productions are carried out in small and artisanal facilities strongly linked to the territory. The lack of the pasteurization step in cheese production preserves the indigenous bacteria responsible, through their enzymatic modification, for some important physicalchemical characteristic. Nevertheless, unpasteurized milk poses a microbiological risk since pathogens are not 
destroyed by the heat treatment. In this study, a microbiological evaluation of raw milk cheeses was carried out and it highlighted a high bacterial load in all the samples tested as reported in previous studies $[16,17]$. Soft cheese, regardless of milk origin, showed in more than $50 \%$ of the samples analysed a total bacterial count above $6 \log \mathrm{CFU} / \mathrm{g}$ whereas pasta filata cheese samples were all below $6 \log \mathrm{CFU} / \mathrm{g}$. This value might be due to the curd stretching step performed in hot water and it has been already reported for similar semihard pasta filata cheeses [18].

Results of Enterobacteriaceae and E. coli enumeration showed a good hygienic level in the samples tested: out of 245 samples analysed, 25 and 20 were positive for Enterobacteriaceae and $E$. coli, respectively. Soft cheese made from ovine milk was more often contaminated: out of 25 positive samples, 13 and 10 soft ovine cheese samples evidenced Enterobacteriaceae and E. coli, respectively. Despite the small number of positive samples, Escherichia coli presence has to be taken into account since it has been responsible of foodborne outbreaks caused by raw milk cheese consumption [19, 20]. Escherichia coli presence in raw milk cheese may indicate a milk contamination of faecal origin or can be linked to mammary infections. Additionally, ruminants are a reservoir for $E$. coli and defecation during milking is considered a critical event for milk contamination; therefore, good milking and hygiene practices must be maintained [21].

The high prevalence of SCP in raw milk cheese is well known [22], and our results are in agreement with other authors who reported a prevalence close to $100 \%$ in raw milk cheese [23] and at the retail level [24]. Nevertheless, our study showed that $42.86 \%$ of the retail samples analysed do not respond to the standards established by the EU, and moreover, 3 samples tested positive for enterotoxins. Despite $S$. aureus being one of the most common causes of mastitis in dairy animals [25] and one of the major foodborne pathogens worldwide [26], food poisoning outbreak linked to raw milk cheese consumption has been rarely reported [27]. Differently, it is generally believed that coagulase-negative Staphylococci, such as S. epidermidis and S. warneri, isolated in two positive samples, have low pathogenic potential. Our results are then in agreement with authors who have shown how coagulase-negative Staphylococci already represent a concern due to their ability to produce enterotoxin and to contain many virulence factors and antibiotic resistant genes [28]. Staphylococci can contaminate milk directly from clinical or subclinical mastitis but environment including human handling can also be a major contamination source; thus, improvements in production hygiene and selection of raw materials are strongly recommended.

In all tested samples, Listeria monocytogenes was never detected; this could be due to the presence of the endogenous microbiota of raw milk playing an inhibitive action on L. monocytogenes [29]. Beyond, listerial contamination may occur in many steps of the production chain: recently, no differences of prevalence between raw milk and pasteurized milk cheese have been reported [30] and postprocessing contamination still represents one of the major causes of cheese contamination with L. monocytogenes [29].
Salmonella has never been detected in all samples tested. Nevertheless, raw milk cheese has been recently linked to a Salmonella outbreak with 103 human cases linked to bovine raw milk cheese consumption [31].

\section{Conclusion}

Raw milk cheese still represents a concern in the EU including Italy where consumers are significantly more willing to buy raw milk cheeses than pasteurized milk cheese [32]. Raw milk cheeses, analysed in this study, can be considered as a low risk food due to the absence of major foodborne pathogens such as Salmonella and Listeria monocytogenes. The high prevalence of Staphylococcus and enterotoxin presence in 3 samples represent a concern and suggest a need for improvement of good manufacturing practice and milking operation; additionally, the improvement of the sanitary status of the herd is be desirable.

\section{Data Availability}

The quantitative data used to support the findings of this study are available from the corresponding author upon request, in excel database format.

\section{Conflicts of Interest}

The authors declare that there are no conflicts of interest regarding the publication of this article.

\section{References}

[1] L. Marilley, "Flavours of cheese products: metabolic pathways, analytical tools and identification of producing strains," International Journal of Food Microbiology, vol. 90, no. 2, pp. 139-159, 2004.

[2] P. F. Fox and A. L. Kelly, "Indigenous enzymes in milk: Overview and historical aspects-Part 2," International Dairy Journal, vol. 16, no. 6, pp. 517-532, 2006.

[3] F. Elotmani, A. M. Revol-Junelles, O. Assobhei, and J. B. Millière, "Characterization of anti-Listeria monocytogenes bacteriocins from Enterococcus faecalis, Enterococcus faecium, and Lactococcus lactis strains isolated from raib, a Moroccan traditional fermented milk," Current Microbiology, vol. 44, no. 1, pp. 10-17, 2002.

[4] N. Gopal, C. Hill, P. R. Ross, T. P. Beresford, M. A. Fenelon, and P. D. Cotter, "The prevalence and control of Bacillus and related spore-forming bacteria in the dairy industry," Frontiers in Microbiology, vol. 6, 2015.

[5] A. C. Camargo, J. J. Woodward, D. R. Call, and L. A. Nero, "Listeria monocytogenes in food-processing facilities, food contamination, and human listeriosis: the Brazilian scenario," Foodborne Pathogens and Disease, vol. 14, no. 11, pp. 623-636, 2017.

[6] EFSA, "The European Union summary report on trends and sources of zoonoses, zoonotic agents and food-borne outbreaks in 2017," EFSA Journal, vol. 16, no. 12, p. 20449, 2018.

[7] E. Dalzini, V. Bernini, B. Bertasi, P. Daminelli, M. N. Losio, and G. Varisco, "Survey of prevalence and seasonal variability of Listeria monocytogenes in raw cow milk from Northern Italy," Food Control, vol. 60, pp. 466-470, 2016. 
[8] D. van Cauteren, N. J.-d. Silva, F. X. Weill et al., "Outbreak of Salmonella enterica serotype Muenster infections associated with goat's cheese, France, March 2008," Eurosurveillance, vol. 14, no. 31, 2009.

[9] J. M. Ruzante, J. E. Lombard, B. Wagner et al., "Factors associated with Salmonella presence in environmental samples and bulk tank milk from US dairies," Zoonoses Public Health, vol. 57, no. 7-8, pp. e217-e225, 2010.

[10] L. M. Jablonski and G. A. Bohach, "Staphylococcus aureus," in In food microbiology fundamentals and Frontiers, M. P. Doyle, L. R. Beuchat, and T. J. Montville, Eds., pp. 353-375, American Society for Microbiologyand a. Rasooly, Washington, 1997.

[11] N. Balaban and A. Rasooly, "Staphylococcal enterotoxins," International Journal of Food Microbiology, vol. 61, no. 1, pp. 1-10, 2000.

[12] S. Derzelle, F. Dilasser, M. Duquenne, and V. Deperrois, "Differential temporal expression of the staphylococcal enterotoxins genes during cell growth," Food Microbiology, vol. 26, no. 8, pp. 896-904, 2009.

[13] S. Johler, P. Giannini, M. Jermini, J. Hummerjohann, A. Baumgartner, and R. Stephan, "Further evidence for staphylococcal food poisoning outbreaks caused by egc-encoded enterotoxins," Toxins, vol. 7, no. 3, pp. 997-1004, 2015.

[14] E. O'Loughin, "Escherichia coli O157:H7," The Lancet, vol. 349, no. 9064, p. 1553, 1997.

[15] Commission Regulation (EC), "Amending regulation (EC) no. 2073/2005 on microbiological criteria for foodstuffs," Official Journal of European Union, vol. L322, no. 2007, pp. 12-29, 2007.

[16] E. Pesenti, C. Bernardi, V. M. Moretti et al., "Potentiality of the use of starter culture in PDO Strachitunt production on chemical-physical and microbiological features: a pilot study," LWT, vol. 98, pp. 124-133, 2018.

[17] C. F. A. M. Penna, S. H. C. Sandes, M. R. Souza et al., "Lactic acid microbiota identification in water, raw milk, endogenous starter culture, and fresh Minas artisanal cheese from the Campo das Vertentes region of Brazil during the dry and rainy seasons," Journal of Dairy Science, vol. 99, no. 8, pp. 60866096, 2016.

[18] R. Di Cagno, I. De Pasquale, M. De Angelis, and M. Gobbetti, "Accelerated ripening of Caciocavallo Pugliese cheese with attenuated adjuncts of selected nonstarter lactobacilli," Journal of Dairy Science, vol. 95, no. 9, pp. 4784-4795, 2012.

[19] C. Gaulin, E. Levac, D. Ramsay et al., "Escherichia coli O157:H7 Outbreak Linked to Raw Milk Cheese in Quebec, Canada: Use of Exact Probability Calculation and Case-Case Study Approaches to Foodborne Outbreak Investigation," Journal of Food Protection, vol. 75, no. 5, pp. 812-818, 2012.

[20] J. T. McCollum, N. J. Williams, S. W. Beam et al., "Multistate outbreak of Escherichia coli O157:H7 infections associated with in-store sampling of an aged raw-milk Gouda cheese, 2010," Journal of Food Protection, vol. 75, no. 10, pp. 17591765, 2012.

[21] A. Martin and L. Beutin, "Characteristics of Shiga toxinproducing Escherichia coli from meat and milk products of different origins and association with food producing animals as main contamination sources," International Journal of Food Microbiology, vol. 146, no. 1, pp. 99-104, 2011.

[22] Å. Rosengren, A. Fabricius, B. Guss, S. Sylvén, and R. Lindqvist, "Occurrence of foodborne pathogens and characterization of Staphylococcus aureus in cheese pro- duced on farm-dairies," International Journal of Food Microbiology, vol. 144, no. 2, pp. 263-269, 2010.

[23] P. Cremonesi Cremonesi, G. Perez, G. Pisoni et al., "Detection of enterotoxigenic Staphylococcus aureus isolates in raw milk cheese," Letters in Applied Microbiology, vol. 45, no. 6, pp. 586-591, 2007.

[24] N. Costanzo, M. Rodolfi, R. Musarella et al., "Microbial quality evaluation of grated cheese samples collected at retail level in Calabria (Italy)," Journal of Food Safety, vol. 38, no. 6, article e12530, 2018.

[25] C. Ceniti, D. Britti, A. M. L. Santoro et al., "Phenotypic antimicrobial resistance profile of isolates causing clinical mastitis in dairy animals," Italian Journal of Food Safety, vol. 6, no. 2, 2017.

[26] J.-A. Hennekinne, M.-L. De Buyser, and S. Dragacci, "Staphylococcus aureus and its food poisoning toxins: characterization and outbreak investigation," FEMS Microbiology Reviews, vol. 36, no. 4, pp. 815-836, 2012.

[27] A. Ostyn, M. L. de Buyser, F. Guillier et al., "First evidence of a food poisoning outbreak due to staphylococcal enterotoxin type E, France, 2009," Eurosurveillance, vol. 15, pp. 10-13, 2010.

[28] W. Chajęcka-Wierzchowska, A. Zadernowska, and J. Gajewska, "S. epidermidis strains from artisanal cheese made from unpasteurized milk in Poland - Genetic characterization of antimicrobial resistance and virulence determinants," International Journal of Food Microbiology, vol. 294, pp. 55-59, 2019.

[29] A. Maffre, M. S. Schvartzman, M. Sanaa, F. Butler, F. Tenenhaus-Aziza, and K. Jordan, "Modelling the fate of Listeria monocytogenes during manufacture and ripening of smeared cheese made with pasteurised or raw milk," International Journal of Food Microbiology, vol. 145, pp. S31-S38, 2011.

[30] V. Martinez-Rios and P. Dalgaard, "Prevalence of Listeria monocytogenes in European cheeses: A systematic review and meta-analysis," Food Control, vol. 84, pp. 205-214, 2018.

[31] S. Le Hello, C. Guerrisi, R. Lailler et al., "Disentangling a complex nationwide Salmonella Dublin outbreak associated with raw-milk cheese consumption, France, 2015 to 2016," Eurosurveillance, vol. 24, no. 3, 2019.

[32] C. Pasta, G. Cortese, P. Campo, and G. Licitra, "Do biodiversity factors really affect consumer preferences?," Progress in Nutrition, vol. 11, pp. 3-11, 2009. 


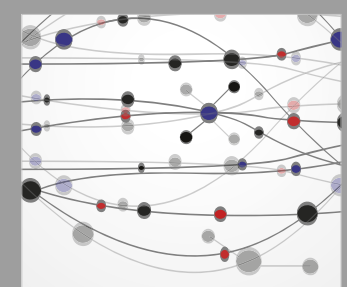

The Scientific World Journal
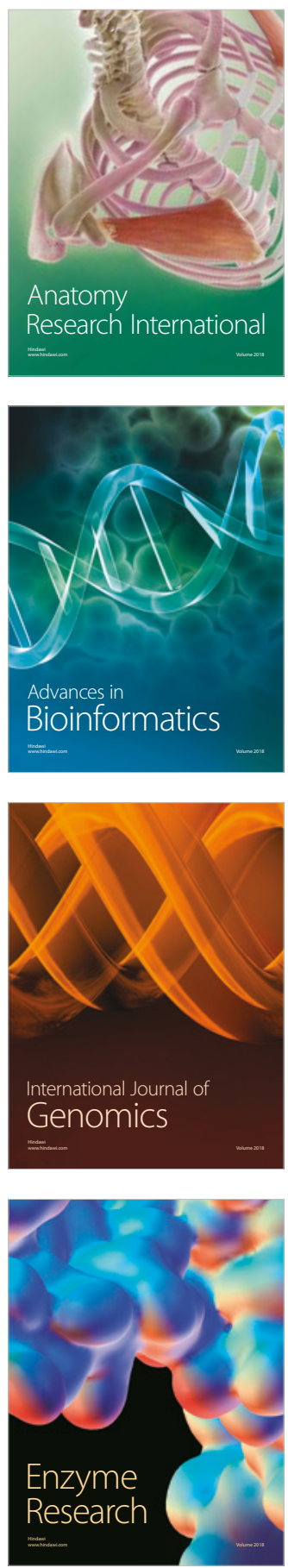
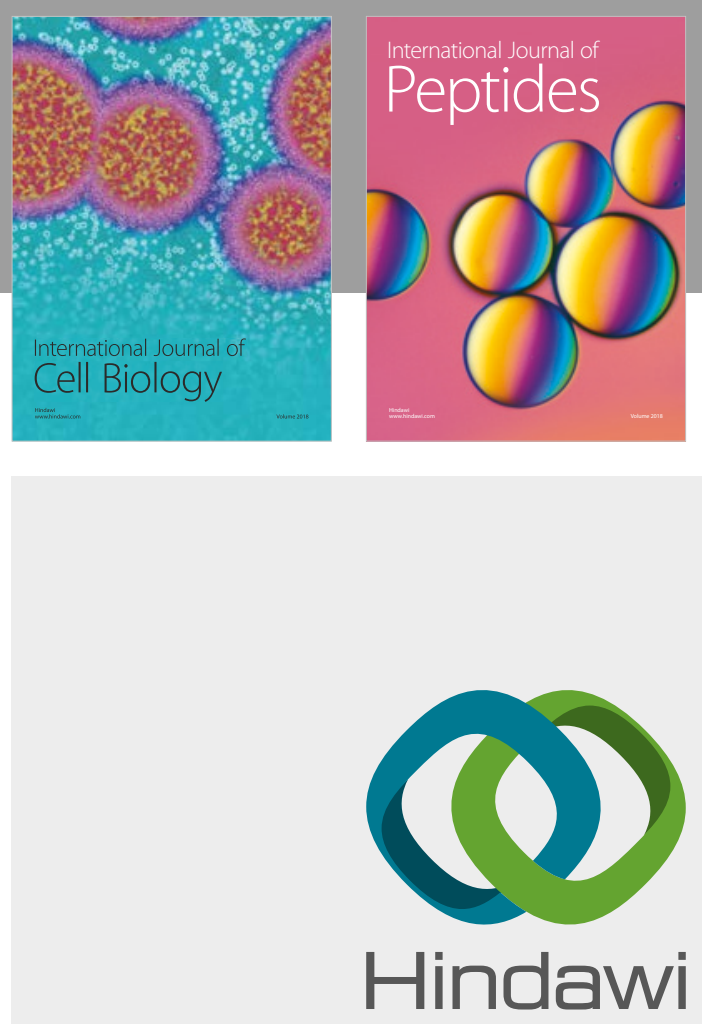

Submit your manuscripts at

www.hindawi.com
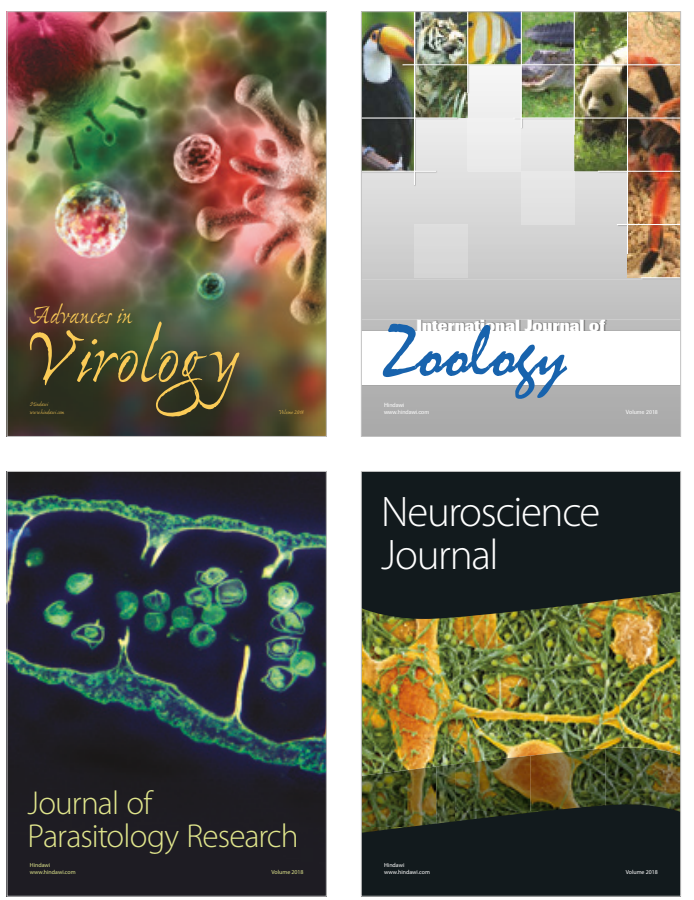
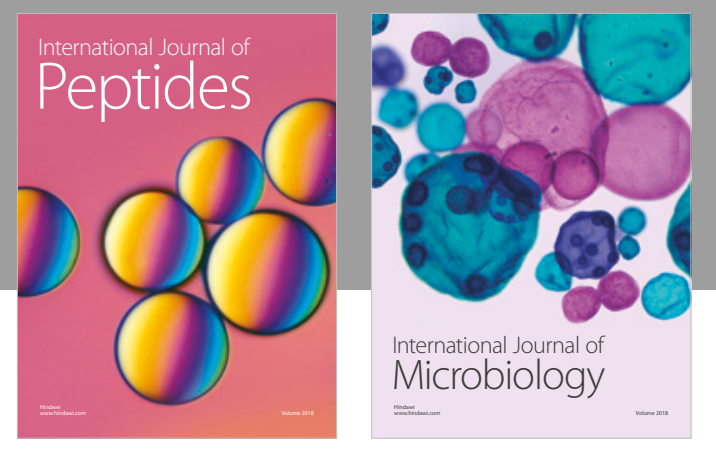

nternational Journal of Microbiology
Journal of
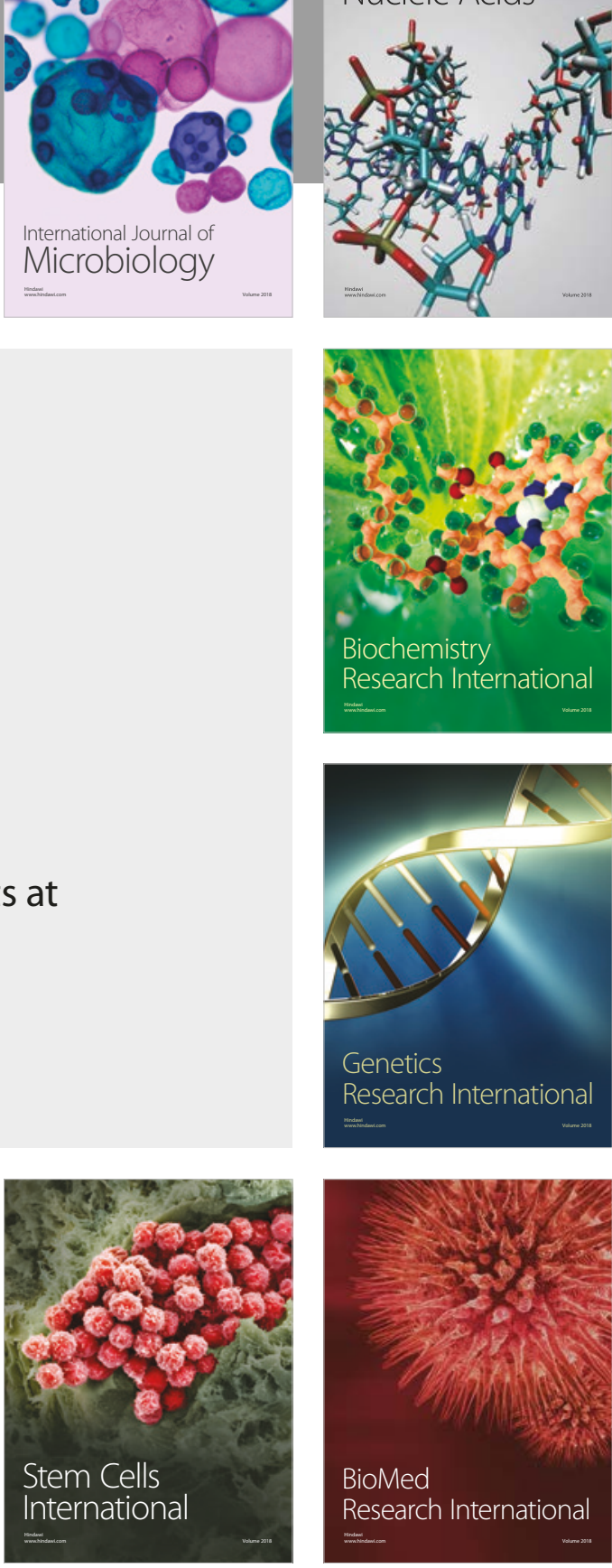
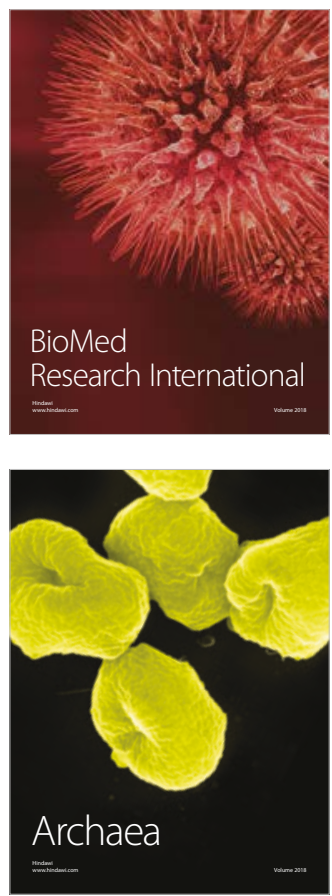